\title{
DO NOT-FOR-PROFITS MAKE A DIFFERENCE IN SOCIAL SERVICES? A SURVEY STUDY
}

\author{
BY
}

\author{
PIERRE KONING, ${ }^{*}$ JOËLLE NOAILLY** AND SABINE VISSER***
}

\begin{abstract}
Summary
This paper provides a survey of the empirical literature on the relative performance of not-forprofit (NFP) organisations for three specific sectors. In particular, we compare the quality and accessibility of services that are provided by hospitals, child care organisations and welfare-towork (WTW) organisations. Various mechanisms may explain the comparative advantages and disadvantages of not-for-profit organisations, as well as the origins of NFPs. We link these explanations to the actual relative performance of NFPs and discuss the implications for the government in mixed markets, where both for-profit (FP) and NFP organisations are. Our general finding is that NFPs do not make a difference on performance outcomes vis-à-vis FP organisations. It seems that the degree of competition, as well as regulatory policies are more important determinants of market performance.
\end{abstract}

Key words: firm organisation, legal status, non-profit organisations, public enterprise

JEL Code(s): L22, L3

\section{INTRODUCTION}

Although their role and form have changed substantially, not-for-profit (NFP) organisations still serve as important delivery mechanisms of public services. Advocates of NFPs argue that rents are used in the interest of society as a whole, that they have more public sector motivation than for-profit (FP) firms and are better capable of meeting local needs. Examples include parental support in non-profit childcare organisations or case-workers in the social sector that are intrinsically motivated to get less advantaged unemployed clients back to work. Following this line of reasoning, the 'Commissie Wijffels' stresses the importance of fostering and stimulating private NFP organisations (Ministerie van Justitie (2006)).

* Corresponding author: CPB Netherlands Bureau for Economic Policy Analysis, P.O. Box 80510, The Hague, 2508 GM, The Netherlands; e-mail: P.W.C.Koning@cpb.nl

** CPB Netherlands Bureau for Economic Policy Analysis, P.O. Box 80510, The Hague, 2508 GM, The Netherlands; e-mail: J.Noailly@cpb.nl

*** CPB Netherlands Bureau for Economic Policy Analysis, P.O. Box 80510, The Hague, 2508 GM, The Netherlands; e-mail: S.S.Visser@cpb.nl 
Opponents to NFP organisations, however, doubt the value added in terms of quality and accessibility of services provided by NFPs. In particular, they argue that for both employees and consumers the distinction between profit and non-profit status has become largely irrelevant. Like FPs, NFP organisations may encounter internal agency problems in monitoring their employees. These problems may be larger than for FPs, since there is no market in ownership shares to prevent 'managerial shirking'.

For policy makers, assessing the role of NFPs in mixed markets with FPs is certainly nontrivial. One may argue that NFPs are just a fact of life, and should be treated similar to private FP organisations. Still, the formal missions of NFPs often show strong similarities with those of the government. NFPs generally aim at increasing the quality and accessibility of products, which may be an argument to stimulate NFPs, e.g. by favourable tax conditions or favouring NFPs in public contracting processes or subsidisation rules. $^{1}$ At the same time, one should be aware that the non-profit condition is not a sufficient condition to warrant social goals. There is a risk that rents provided by the government induce NFPs to raise wages, create inefficiencies, or crowd out private donations or donated labour. These may be important arguments not to subsidise or favour NFPs, thus maintaining a level playing field between FP and NFP organisations.

This paper surveys the empirical literature on the relative performance of NFP organisations in mixed markets for three specific sectors. In particular, we compare the quality and accessibility of services that are provided by hospitals, child care organisations and welfare-to-work (WTW) organisations providing training and counselling services for job seekers. Various mechanisms may explain the comparative advantages and disadvantages of NFP organisations, as well as the origins of NFPs. We link these explanations to the actual relative performance of NFPs and discuss the implications for the government in mixed markets, where both FP and NFP organisations are. Thus, we combine recent advances in both theoretical and empirical economic analyses, so as to expose the efficiency and effectiveness of NFPs.

In the survey, our focus is on three sectors that are commonly labelled as 'social services': the hospital sector, the childcare sector and WTW services. The first aspect that unites these three sectors is that they are subject to substantial informational problems that may undermine the quality and accessibility of services. In this setting, the government either aims at services to be sufficiently accessible, or to warrant quality standards. Second, a common

1 In this respect, the most important tax advantage of NFPs in the Netherlands is the exemption from corporate taxes on surpluses they make. Fiscal authorities may deviate from this rule if they doubt the official mission of the NFP organisation, but this rarely occurs in practice. In addition to this, there are more aspects that are distinct from the fiscal treatment of FP organisations, particularly for small NFP organisations (see Koning et al. (2007)). 
feature is that organisations in these sectors - both FPs and NFPs - are often large, with substantial professional standards that have to be met by their employees. This means that NFP organisations cannot rely upon voluntary work as an important provider of labour. This contrasts to e.g. ideological or religious organisations, where voluntary work is the dominant provider of labour. $^{2}$ Third, in the sectors - and for many countries - both FP and NFP organisations operate as providers of services ('mixed markets'). This means that FPs and NFPs in principle are competitors. There also may be mixed markets where public organisations provide services as well. ${ }^{3}$

For the Netherlands, empirical evidence on the relative performance of NFPs vis-à-vis FPs is virtually absent. So far, in the international literature most evidence is based on data from the US and Canada. When surveying the literature, we therefore concentrate on these two countries. Obviously, from these results we cannot make inference that can be fully translated to other countries. Still, we believe that insights from the literature provide useful guidance on the determinants of the performance of NFPs, as well as the relative importance of legal status in explaining market outcomes, compared to e.g. the level of competition or the impact of regulatory measures by the public sector.

In what follows, we first discuss in Section 2 the major theoretical notions underlying the origins of NFPs, as well as their advantages and disadvantages. Section 3 surveys the empirical literature, whereas Section 4 discusses the interpretation of this literature. Finally, Section 5 discusses policy options, as well as some broader notions on the role of NFPs.

\section{THE ECONOMICS OF NFPS}

\subsection{NFPs and Donated labour}

There are two main structural features that distinguish NFPs from FPs: (i) the 'non-distribution-constraint' and (ii) the absence of owners (Hansmann (1980); Glaeser (2002)). The non-distribution-constraint states that there are strict limits to the appropriation of the organisation's surplus in the form of profits for those who run and control it, such as its members, founders or governors. This contrasts with FPs, where shareholders are the residual claimants. Here, the owner is a shareholder whose aim it is to get a high return rate. Instead, NFPs are not accountable to any owner or shareholder, but are

2 This contrasts to so called 'expressive functions' (see Salamon et al. (2003)), which involve activities for the expression of cultural, religious or policy interests and beliefs, and where volunteer work is the dominant provider of labour.

3 In this study, however, we abstract from markets where public organisations are active. Instead, we concentrate on markets where private FP and private NFP organisations prevail and where the public sector acts as a regulator. 
expected to benefit beneficiary stakeholders - that is, individual consumers, or society as a whole - by providing products on favourable terms. In this sense, NFPs can be regarded as 'failure correcting devices' that allocate more effort to the quality and the accessibility of their products. Thus, in our analysis we may think of markets with FPs only as a reference point, with a relatively high overall efficiency but a substantial role of market failures as well. When NFPs enter into these markets, this may reduce the consequences of market failures, while hampering efficiency at the same time. More specifically, NFPs, may increase the quality and accessibility of services by correcting market failure, but these effects can be (partially) offset by managerial efficiencies ('rent extraction').

Donated labour is regarded as one of the key ingredients for the success of NFPs. NFPs are better capable of carrying out their missions when they attract workers that are, at least to some extent, intrinsically motivated to fulfil these missions. Stated differently, this means that managers and workers are not driven by monetary incentives only, but also by the wellbeing of their beneficiary stakeholders - i.e. they are willing to work beyond their strict job description and donate extra effort than what was explicitly contracted. Following this line of arguing, one may expect wages to be lower in NFP than in FP organisations, with voluntary (unpaid) work as the most extreme form of donated labour. ${ }^{4}$ We also may expect NFPs to receive more private donations than FPs do. Thus, the provision of donated labour and private donations can be considered as a mechanism explaining why NFPs actually can make a difference over FP firms, particularly in sectors where quality aspects of output are hard to contract upon (Francois (2001)). The very lack of residual claimants or profit motive provides a valuable commitment to the worker at the same time: it tells that, in principle, there is no individual or group standing to gain from converting donated effort into extra profit for themselves. Nobody higher in the organisation has an incentive to cut back on elements of service provision because nobody in the organisation will gain by doing so.

Ideally, the non-distribution-constraint of NFPs acts as a plain signal to potential providers of donated labour. When profits are prohibited, firms can credibly commit to public goals, thus attracting workers that support these goals as well. In practice, however, the interaction between the non-profit status and donated labour is nontrivial. NFPs often have problems in formulating concrete missions, or worse, its management may be inclined to exploit

4 In contrast, Francois (2002) argues that labour donation mechanisms may be hampered by workers that want to free-ride on the effort of their co-workers, anticipating that they are willing to donate labour in their place. NFPs may combat this problem by offering higher ('efficiency') wages, thus reducing such moral hazard problems. 
the incontractability of their activities. ${ }^{5}$ Stated differently, the formal restriction on the appropriation of profits is a necessary, but not a sufficient condition to favour the beneficiary stakeholders. Instead of improving the quality and accessibility of services, the management and workers of NFPs may use other mechanisms for their own interest, for instance by increasing wages or decreasing the number of working hours. We return to this issue, and other related inefficiencies in more detail in Section 4.

\subsection{NFPs as Market Failure Devices}

In the literature, there is a variety of market failures providing an opportunity for NFPs to outperform FPs. Stated differently, there is a number of market failures that may occur in markets with profit oriented firms only. In the following, we list four of these market failures that are most prevalent in explaining the rationale of NFPs: (i) asymmetric information, (ii) externalities, (iii) market power and (iv) distributional or merit good concerns. ${ }^{6}$ In this list, distributional and merit good arguments can be labelled as equity concerns, which therefore cannot be characterised as market failures in a narrow sense (i.e. an efficiency argument).

\subsubsection{Asymmetric Information}

The delivery of services often comes with substantial moral hazard problems: as many quality aspects are hard to observe by consumers, producers may be inclined to reduce the quality of their services. In the literature, this argument is often mentioned as the major rationale for NFPs (see e.g. Hansmann (1980)). Particularly in the social services sector, doctors, nurses, case-managers and nursery school teachers are better informed on the quality of services they provide than consumers. Thus, the non-profit status may act as a signal that service providers will not exploit their informational advantage and act in the interest of consumers. Generally, the long term consequences of service interventions are hard to measure and contract upon - in particular the future effects on health (hospitals), cognitive and social skills (child care) and the durability of new jobs (WTW). Similarly, it is difficult to determine the net effect of service providers, that is, the extent to which they influence outcome variables, or factors that are beyond their reach. This is particularly relevant to the WTW-sector. Here, re-employment rates are driven by a variety of factors that WTW-firms cannot control - for instance the business cycle.

5 Obviously, FP organisations may also have problems in formulating concrete missions, and act accordingly. In this process, however, they will experience the pressure from their residual claimants.

6 In the literature, the (quasi-) public good argument is often mentioned as one of the key market failures. Within the context of (social) services, however, this argument is not relevant. 
Asymmetric information problems may not only result in quality problems, but also limit the accessibility of services. Such adverse selection problems typically occur in the insurance and lending industry, where insurers and bankers are, to a large extent, unable to differentiate between the individual risks of consumers. Given a certain premium rate, only high risk individuals are likely to buy insurance. Thus, insurance may not be profitable, leading to underinsurance. Within the context of the three cases of interest, adverse selection is particularly important in the care sector, where insurers bear the individual health risk of consumers. Without any intervention, the market is likely to lead to underinsurance against health costs. Usually, adverse selection problems call for a regulatory role for the public sector (e.g. compulsory insurance), rather than by NFP intervention - for instance by establishing a universal acceptance obligation for insurers.

\subsubsection{Externalities}

The production and consumption of products may have unintended consequences on parties other than the consumer that cannot be reflected in individual prices. With respect to the social services sector, these externalities are mostly positive. Similar to public organisations, positive externalities may be a rationale for NFP organisations to exist. NFPs may facilitate managers or workers that are intrinsically motivated to internalise externalities.

When regarding the three cases, externalities may form a rationale for NFP provision for WTW services in particular. If WTW trajectories indeed reduce unemployment levels and create permanent employment, this may lead to a reduction in crime in the neighbourhood. In this way, WTW services may have positive externalities. For the childcare sector, various studies do find a positive relation between the quality of childcare and the cognitive and social development of the child (Blau and Currie (2004)). This however does not necessarily point at externalities, as it may be that similar outcomes are achieved when children are raised at home. ${ }^{7}$ For hospitals, a similar line of reasoning applies: externalities may exist, but there is no apparent role for NFPs here. Externalities of hospital services occur when diseases are infectious. By curing or preventing infectious diseases, these benefits do not exclusively accrue to the individual patient. The presence of such externalities may be an argument to subsidise various treatments or medicines. In modern Western countries, however, this role is usually taken care of by the public sector.

7 The case for tax externalities seems much stronger, i.e. the use of child care is commonly accompanied by additional labour supply, thus increasing tax revenues. 


\subsubsection{Market Power}

Firms may derive market power from scale advantages, for instance when local markets where they operate are characterised by regional monopolies. In principle, NFPs are less likely to exploit market power by raising prices and reducing the delivery of services than FPs are. As a result, market power as a rationale for NFPs - particularly in small and isolated communities is connected to the distributional concerns argument. This holds for both the provision of child care and hospitals. For WTW-services, the market power argument is less strong, as scale advantages are far less important here (see e.g. CPB (2000)).

\subsubsection{Distributional Concerns}

NFPs are often (formally) driven by a mixture of distributional and paternalistic concerns. NFPs may aim at a sufficient (physical or financial) access to services or a minimum provision of services for all consumers under all circumstances (i.e. health care). This means that NFPs focus on the provision of services in specific (isolated) areas and for specific target groups. In contrast to FPs, NFP organisations may have less incentives to "cream-skim" the most profitable consumers or activities. For instance, NFPs may provide reasonably priced child care or health facilities for low income families. Similarly, NFPs may help unemployed workers with bad labour market prospects. Note that these arguments may also be a reason for public sector intervention (i.e. general tax allowances), thus reducing the scope for NFPs.

\section{EMPIRICAL EVIDENCE}

Informational asymmetries, externalities, market power and distributional concerns may all be a rationale for NFPs to exist. These market failures provide NFPs with the opportunity to make a difference vis-à-vis FPs. Within this context, "making a difference" implies that NFPs outperform FPs on some aspects: costs and efficiency, quality, quantity (accessibility), or its focus on specific consumers or (local) market segments. In what follows, however, we will focus on the quality and accessibility of services that are provided. In doing this, we concentrate on the current state of the art of the empirical literature that compares (individual) FP and NFP organisations or individual patients of FP and NFP hospitals, starting from the early nineties. More specifically, we primarily have selected studies where quality and accessibility are (sufficiently) controlled for by any variation in consumer types (e.g. low and high income, or low or high health risks) and variation in price levels of the services that are provided. Thus, we are able to concentrate on quality and accessibility differentials, conditional on a certain price level for both organisation types. This particularly holds for the discussion of hospitals and child care organisations, where we discuss the link between income, prices and 
quality. For the welfare-to-work services, unfortunately, the literature does not offer any insight in price differentials between FPs and NFPs.

\subsection{Hospitals}

There is a large literature in the US that addresses the difference in quality between FP and NFP hospitals, mostly in terms of their mortality rates. ${ }^{8}$ Overall, there appears to be no systematic difference in quality. Recently, Eggleston et al. (2006) have identified various factors that explain the diversity of results that are found in the literature. ${ }^{9}$ First, the unit of analysis is important: studies using data at patient level generally find no differences between the quality of FPs and NFPs, while studies using aggregated data at the hospital level generally find that NFPs perform better. Second, quality differentials between FP and NFP hospitals are strongly related to the period of investigation. In particular, after 1990 authors generally find no differentials between the organisation types. Eggleston et al. (2006) argue that this result stems from a recent convergence among ownership forms, and better controls for unobserved heterogeneity in patients. They also stress that recent studies take better account of the role of competition. That is, increases in competition between hospitals of the last decades may well explain the convergence between FP and NFP hospitals. At the same time, it is important to note that in many countries with FPs and NFPs, including the US, health insurance is compulsory and the provision of service is regulated by the public sector. This also limits the room for quality and accessibility differentials.

Regarding cream-skimming and access to care, the evidence is mixed. Here, most of the literature falls down to the question of whether FP and NFP hospitals pursue objectives that differ from profit maximisation. If NFP hospitals effectively aim to maximise profits, they will tend to drop non-profitable services and cream-skim the most profitable patients, similar to FP hospitals. Sloan (2000) analyses hospital conversions in three US states. He finds that switching from the NFP to the FP status has decreased the probability that a hospital runs potentially unprofitable programs, like AIDS prevention, community health, and rehabilitation programs. This study, however, suffers from substantial selection effects, i.e. hospitals that converted to FP organisations are likely to be hospitals with poor financial performance in the first place. Cutler and Horwitz (2000), who also address conversions from NFP to FP

8 Studies that find the quality of NFP hospitals to outperform that of FP hospitals are: Cutler and Horwitz (2000), Sloan et al. (2001), Gray and McNerney (1986). Reverse results are found in McClellan and Staiger (2000) and Marmore et al. (1986).

9 Another meta-analysis has been done by Devereaux et al. (2002). They find that FP hospitals were associated with increased risk of death. This study has been, however, severely criticised by Eggleston et al. (2006); they argue that the studies used overlapping data from the same patients and same hospitals. 
hospitals, find that "having FP hospitals in the market appears to cause NFP hospitals to adopt the same moneymaking measures employed by FP hospitals". Duggan (2000) analyses the response of FP and NFP hospitals to financial incentives, induced by a policy change aiming at improving quality of care for the poor. He finds no difference: both cream-skimmed patients by avoiding Medicaid and uninsured patients and both used the extra revenues to increase their financial assets, not to improve quality of care. By contrast, Horwitz (2005) finds that both types of hospitals pursue different objectives and that FP hospitals are more profit-seeking than either NFP or public hospitals. When combining the insights from various studies, it appears that the accessibility of services provided is mainly driven by competition in markets: both NFP and FP hospitals are more likely to offer profitable services and less likely to offer unprofitable services when competition is high. Still, when competition is low, NFPs may make a difference by providing services for uninsured patients. Thus, the overall picture that emerges is that NFP hospitals do not make a systematic difference vis-à-vis FP hospitals. It is only in markets with relatively low competition that NFPs may provide a higher level of accessibility of services, particularly for uninsured patients.

\subsection{Child Care}

For the child care sector, the empirical literature distinguishes three aspects of quality: (i) structural quality, which concerns the basic quality of the childcare environment (e.g. furnishings, fire safety and group size); (ii) process quality, relating to the service itself, i.e. teacher-child and peer interactions; and (iii) quality in child outcomes, i.e. the contribution of childcare to the emotional, social and cognitive development of the child. Structural quality is generally easy to observe (and regulate!). Empirical studies mostly find that NFPs on average provide a higher level of structural quality (Mocan (1995), Sundell (2000), Cleveland and Krashinsky (2004, 2005)). Obviously, process quality of childcare services is more difficult to observe than structural quality, and therefore - if NFPs are less susceptive to moral hazard problems - the NFP advantage should theoretically be larger here. The evidence here is, however, more mixed. ${ }^{10}$ Whereas Canadian studies tend to report a significantly positive NFP differential (Cleveland and Krashinsky (2004), Japel et al. (2005)), the most recent and comprehensive US studies do not (Morris and Helburn (2000), Blau and Mocan (2002)). The degree of regulation may be important

10 Quality that is hard to observe, is naturally also hard to measure. In order to compare levels of process quality, economists use a scale that was designed by child psychologists, which measures the level of various aspects of quality during onsite visits by professional observers called the Early Childhood Environment Raring Scale (ECERS) or Infant- and Toddler Environment Rating Scale (ICERS). 
in determining the extent to which NFPs and FPs can behave differently. In particular, Morris and Helburn (2000) and Blau and Mocan (2002) find a positive NFP differential only in the state with the least stringent regulatory framework regarding quality of services. Also market size seems of importance here: Cleveland and Krashinsky (2005) find that a NFP advantage only materialises in markets with sufficiently high demand. Presumably, in (homogeneous) markets with low demand, NFPs are forced to compete with FPs on price, limiting their ability to offer higher quality (at higher costs). Finally, the third aspect of childcare quality, i.e. quality in child outcomes, is most difficult to observe, as the effect of high quality childcare on child development may take considerable time to materialise. Sundell (2000) finds no significant differences in child outcomes between NFP and FP childcare providers. Thus, overall the empirical results on a NFP advantage in providing high-quality childcare are rather ambiguous.

Distributional concerns also feature in the market for childcare. Most studies indeed find that NFP childcare organisations are on average more likely to serve low-income families (Cleveland and Krashinsky (2004), Whitebook et al. (1990), Morris and Helburn (2000) and Blau and Mocan (2002)). Whitebook et al. (1990), however, find that the relation between family income and mode of childcare provision is not straightforward - i.e. linear. While children from low-income families are more likely to attend NFP childcare centres than children from middle-income families, the same holds true for children from high-income families. High-income families in the sample were most likely attracted by the higher average quality offered in the NFP centres. Oddly, both high-income and low-income families displayed a higher willingness-to-pay than middle-income families. ${ }^{11}$ The only study to dissent is Japel et al. (2005). They find that children with a less favourable socio-economic background are more likely to attend FP day-care centres. In addition, they find that while in FP centres the quality of service varies with the socio-economic status of its clientele (i.e. children from low-income families received the lowest quality of care), this phenomenon does not occur in NFP centres. This last observation again lends credence to the idea that NFPs are less likely to compromise on quality when faced with a less affluent clientele.

Summarising, there is no clear systematic evidence in the empirical literature that NFP childcare providers are more trustworthy in producing high quality childcare. Remarkably, the only difference between FP and NFP providers that emerges from the literature regards aspects of quality that are easy to observe and regulate. As in the case of hospitals, direct competition

11 A possible explanation for this, is that low-income families are badly informed on the quality of services. For them, the non-distribution-constraint may be particularly valuable, so they choose for NFP child care. At the same time, high-income families may be better informed, but prefer higher quality due to income effects. 
between NFPs and FPs inhibits the extent to which the two organisational forms may behave differently. With respect to differentiation or accessibility of care, there are only some indications that NFPs are more willing to service low-income markets.

\subsection{Welfare-to-Work}

Similar to the health care and child care sectors, information asymmetries are probably the most important market failure in the WTW-sector, where organisations provide job training and counselling services for job seekers. In most OECD countries, the public sector is the major customer of WTW-services, aiming at getting benefit recipients back to work. Here, the key question is how the government can protect the collective interest when private organisations take care of WTW activities. The non-profit-condition may be one way to ensure two goals that are hard to contract upon: (i) durable jobs; and (ii) avoiding the cream skimming of unemployed clients with a priori good prospects of finding work.

If NFPs make a difference on the quality of services vis-à-vis FP organisations, we would expect the net effectiveness of NFPs to be higher - that is, WTW-services should result in higher re-employment rates or higher wages at placement. So far, there is little empirical evidence that specifically addresses this issue, with Heinrich (2000) and Stoll et al. (2003) as major exceptions. Heinrich (2000) studies the effectiveness of 637 local service providers of JTPA $^{12}$-activities in the US for 1984-1993. These service providers can be classified as public non-profits (14\%), private non-profits $(65 \%)$ and forprofits $(21 \%)$. When comparing the outcome variables - wages, job placements - no systematic differences between organisation types are found. In the short run, at the moment of termination of a program, FPs seem to outperform NFPs, but these differences do not last when considering the first post-program quarters. Stoll et al. (2003) study the outcomes of 'Community Based Organisations' (CBO's) - a specific type of NFPs that is relatively strongly rooted in local areas - in the Boston area of the US. In this study, CBO's seem to perform better than other NFPs and FP organisations in terms of job placement rates. In terms of placement wages, however, CBO's perform less. We therefore conclude that NFPs are not consistently more effective or ineffective than FPs.

The second argument for NFPs may be rooted in cream skimming. Heckman et al. (2002) analyse cream skimming in WTW services in great detail. They argue that it is associated with modest efficiency gains or losses only. This means that combating cream skimming must come from distributional 
concerns. Heinrich (2000) however does not find any systematic differences between organisation types here: for instance, in the period of investigation, FP organisations were more likely to serve welfare recipients, clients with basic skills deficiencies, but less likely to serve high-school dropouts. In addition, FPs were even somewhat more likely to provide more intensive types of training services to participants. In contrast, Stoll et al. (2002) find evidence that CBO's in Boston train participants with more 'barrier characteristics' than others.

From these findings, we may conclude that NFP WTW-providers do not systematically make a difference to FP organisations, or public offices. Still, NFPs are often favoured in contracting processes, NFP organisations may receive tax-deductible donations and are often exempt for local property and sales taxes (Heinrich (2000)). Generally, it seems NFPs cannot effectively use these advantages by favouring their clients, or specific groups of workers.

\section{INTERPRETING THE EVIDENCE}

\subsection{Rents and Rent Extraction}

When combining the insights from the empirical literature, the picture emerges that NFPs do not systematically make a difference with respect to FP social services organisations. It is only in specific circumstances and for specific services that NFPs serve different market segments or provide services with higher quality. In particular, for the three markets under investigation, we only find some evidence for a wider accessibility of hospital and child care services for specific groups and higher quality when regulatory measures by the public sector are virtually absent or when competition is low. Under these conditions, it seems that NFPs can make a difference with respect to FPs.

In order to interpret the results in more detail, our primary interest lies in the non-profit-condition of NFPs. Essentially, the evidence so far can be interpreted in two ways: (i) NFPs do not attract a substantial amount of donated labour; or (ii) (ex ante) rents of NFPs are lost by managerial inefficiencies ('rent extraction'). Both explanations may also be interrelated: if NFPs are susceptive to inefficiencies, individuals may be less willing to donate labour. In practice, the efficiency of NFPs can be hampered by the relatively strong position of its management and workers, as they lack the control of shareholders that FP organisations have. In principle, NFPs may have alternative supervisors, but these will have a lower interest in efficiency gains, as these will not accrue to them. Also, the dynamic efficiency of NFPs - i.e. their capacity to attract capital for innovations - is hampered by the absence of shareholders. In contrast to FP organisations, NFP organisations rely upon donations and private equity only, thus limiting their ability to attract new capital (Gradus and Bovenberg (2001)). 
There are three ways to empirically expose possible inefficiencies or rents extraction in NFP organisations: (i) by wage differentials; (ii) comparing costs and efficiency measures in general; and (iii) analysing the response of NFPs to changes in competition. We now discuss the evidence on these three issues.

\subsubsection{Wage Differentials}

Compared to FP organisations, NFPs may have an advantage in attracting donated labour. When workers expect the organisation not to extract the surplus that is associated with lower wage costs, they may accept lower wages than in a FP setting. There is, however, another specific feature of NFPs with opposite effects: as NFP organisations lack the control of shareholders, its management and workers may be tempted to increase wages.

When considering the social services sectors, wage comparisons between FP and NFP organisations are mostly directed towards hospitals and child care organisations. Ruhm and Borkoski (2000) find FP hospital workers to have similar wages as NFP hospital workers. In contrast, Roomkin and Weisbrod (1997) do find differences between the two types of organisations, but this concerns the relative importance of fixed and performance related pay, rather than the total wage sum that is paid. In the child care sector, the vast majority of studies suggests that, after controlling for job and education types, wages are higher in the NFP sector (Mocan (1995), Mocan and Terkin (2000), Blau and Mocan (2002), Cleveland and Krashinsky (2004)). Cleveland and Krashinsky (2004), however, argue that the NFP wage premium can be explained by higher quality of services provided. This means that workers in NFP organisations provide a higher quality of services, which is rewarded by higher wages. This suggests that NFP workers - similar to workers in FP organisations - are driven by financial incentives as well.

\subsubsection{Costs and Efficiency}

Similar to wage payments, cost and efficiency measures can be informative on the rents and rents extraction of NFP organisations. Lower cost levels and high efficiency levels point towards higher rents - particularly as a result of donated labour - whereas the opposite suggests rents extraction to be dominant. For the care sector, there is an extensive literature that addresses the efficiency of hospitals. In a recent meta-analysis, Shen et al. (2005) exploit and review this literature as from 1990. They argue that sufficient controls at the level of patients, hospitals and market characteristics are needed for a fair comparison between NFP and FP organisations. In such a setting, little differences between the organisation types are found. Similarly, Mocan (1995) and Blau and Mocan (2002) find no cost or efficiency differentials in the child care sector. Therefore, again the picture emerges that FP and NFP organisations are not that different after all. 


\subsubsection{Market Conduct and Competition}

In markets with limited competition, FP organisations have the opportunity to extract rents by raising prices and (thus) lowering the quantities of services that are provided. As we argued in Section 2, NFPs may counteract this by not exploiting their market power, but acting in the interest of consumers. One way to test for this is by relating FP-NFP differences to the extent of competition in particular markets - that is, to assess the response of NFP and FP organisations to changes in the level of competition, for instance due to mergers. In this setting, the question is whether FPs and NFPs do (or do not) exploit the rents that come with this merger. Empirical research on this question has been initiated by Lynk (1995), who analysed a merger between the two largest NFP hospitals in Grand Rapids, Michigan. Lynk used a conceptual model to argue that the 'cooperative' board of directors would not raise prices. Melnick et al. (1999), however, find ownership status not to influence pricing responses of merging hospitals. Consistent with this, Dranove and Ludwick (1999), Melnick et al. (1999) and Simpson and Shin (1997) all find that NFP and FP hospitals set higher prices in less concentrated markets. Thus, the evidence seems to favour the idea that FP and NFP hospitals are both susceptive to rents extraction. ${ }^{13}$ Hansmann (1996) even characterises the non-profit form as "largely anachronistic" in the hospital industry, with the large share of NFP hospitals to be attributable mainly to capital embeddedness.

For the child care and WTW-sector, the evidence on the conduct of FP and NFP organisations is thinner. Heinrich (2000) finds both types of WTW organisations to respond equally to incentive schemes - that is, both FP and NFP organisations in the US showed a similar increase in re-employment rates when performance incentives in service provider contracts were included. This suggests that moral hazard problems are equally important for the two organisation types.

\subsection{Interaction and Spill-overs}

The observation that FP and NFP organisations do not have different conduct or performance outcomes can be used as an argument not to stimulate NFP organisations. This line of reasoning relies upon the implicit assumption that the conduct and performance of FP (NFP) organisations is not affected by the presence of NFP (FP) organisations. If, however, quality effects spillover from NFP to FP organisations - that is, FP organisations increase their quality in response to the presence of NFP organisations - this may be welfare improving. At first sight, quality differences may then be small or even

13 In a broader study, David (2005) argues that FP and NFP hospitals have largely converged, particularly regarding the size of both types of organisations. 
negligible, but the mere presence of NFPs raises the overall level of quality in a particular market.

Interaction effects between the two organisational forms have received little academic interest. One exception that focuses on mixed markets in which NFPs and FPs coexist, is the analysis by Grabowski and Hirth (2001). These authors test two hypotheses on the effect of NFPs on their for-profit counterparts in the nursing home sector. The first hypothesis is that FP en NFP organisations operate in different market segments, thus ruling out any spillover effects. The second hypothesis is that positive spill-over effects occur, basically as a result of heterogeneity among customer types - that is, some are more or less informed on the quality of services than others are.

The first hypothesis of Grabowksi and Hirth is that NFP organisations focus on the high quality segment of the market exclusively, as they have a competitive advantage over FPs here. This advantage may originate from a managerial preference for higher quality, as well as a staff that values high quality and is willing to donate labour to this end. Thus, the effective costs in this market segment can be lowered below the costs of pure profit maximisers. This picture ties in with the analysis of Lakdawalla and Philipson (2006), who argue that firms with objectives that differ from profit maximisation benefit from reduced marginal costs. If consumers are sufficiently capable of recognising quality, and value it accordingly, NFPs will dominate the higher segment of the market and crowd out FPs. Conversely, in the low quality segment where donated labour will be less prevalent, FPs will dominate. Thus, it is basically the amount of donated labour that raises the average quality level in mixed markets, with spill-over effects being absent.

The alternative hypothesis is that there are quality spill-overs from NFPs to FPs. Here, the key argument is that some consumers are worse informed on quality than others. In a purely FP market, higher shares of ill-informed, quality-unresponsive consumers provide higher incentives to shirk on quality. The non-distribution-constraint, however, allows NFP organisations to credibly commit to high quality. As a result, ill-informed consumers are most likely to be drawn towards the NFP organisations, relying on the fact that their informational disadvantage will not be exploited here. This in turn lowers the share of poorly informed consumers that remains for the FP sector. Due to this composition effect, the penalty on quality shirking increases, thus resulting in higher quality of FP organisations as well. In this sense, such effects can be labelled as spill-overs.

With respect to quality of nursing homes, Hirth and Grabowski find no evidence for the first hypothesis, where a higher NFPs' market share would lead to concentration of FPs in the lower quality segments (i.e. market segmentations). With respect to the spill-over hypothesis, the evidence is mixed: the quality of FP nursing homes is positively related to the market share of 
NFPs, but, remarkably, the overall quality level in the market is not. ${ }^{14}$ Thus, the evidence for spill-over effects from NFP to FP organisations in nursing homes is inconclusive.

\section{POLICY ARGUMENTS AND CONCLUSION}

\subsection{Policy Arguments}

From a policy perspective, the finding that there is no systematic difference between NFP and FP organisations suggests that supporting NFPs in mixed markets is not a wise thing to do. In order to support NFPs, the government should rely upon the fact that NFPs use the advantages of their non-profit status exclusively by making a difference, particularly when it comes to the quality level or accessibility of services that are provided. Rents should not be directed to higher wages, or other inefficiencies that are not to the benefit of consumers and/or society as a whole. There is no (strong) evidence that points in this direction, at least not for the three sectors under consideration. ${ }^{15}$

Next to the lack of evidence that NFPs do make a difference, there are more arguments that do not support the basic ideas underlying NFPs. First, when supposing that NFPs are effective in combating market failures, the question is how important residual market failures are. For instance, one may think of NFP hospitals providing specific services that are not cost effective but beneficial for society - e.g. for equity arguments. Now, if the public sector intends to extend the range of these services, it may further encourage NFPs (as well as FPs) to do so. In the literature, however, the complex connection between NFPs' performance and the size of residual market failures is hardly addressed. So far, there is only evidence that public sector regulation and NFPs may act as substitutes. For example, Mocan (1995) finds NFP child care organisations to provide better quality in North Carolina, where quality regulation was low compared to other states.

A second argument against specific interventions is related to this issue of substitution between NFPs and public sector regulation. Substitution will be strong when performance outcomes are contractable. In this case, the government may apply standard regulatory measures, rather than relying upon the legal status of organisations. In the literature, there is some evidence that NFPs distinguish themselves from FP organisations by focusing on specific

14 Spector et al. (1998) also find no support for spill-over effects.

15 Rents extraction effects can also be magnified when (also) self-interested entrepreneurs decide to opt for the non-profit status to have tax advantages (see Glaeser and Schleifer (2001)). David (2005) is one of the few studies that specifically addresses the decision of (new) entrepreneurs to adopt the FP or NFP status. He argues that changes in tax codes and demand- and population growth have encouraged NFP hospitals in the US to switch ownership type. 
market segments or consumer types. This particularly seems to hold when competition is low in markets, and NFPs have the opportunity to make a difference by increasing the accessibility of services, particularly for low-income families. When such distributional concerns are supported by the government, this, however, does not mean that NFPs should effectively be stimulated just because of their non-profit status. Instead, as the target groups - for instance disadvantaged workers - are well observable and can be contracted upon, the government may consider subsidisation by the target group itself, rather than NFP status. Thus, regulation would involve the use of vouchers to specific consumers in this case, so as to lower the effective consumer prices. ${ }^{16}$ Conversely, if the degree of incontractability, is high and quality is hard to observe, NFPs cannot be effectively substituted by public sector regulation. As standard regulatory measures are then ineffective, this may be an argument for NFPs. ${ }^{17}$

The third argument against favouring NFPs is that of crowding out effects of donated labour and private donations. Crowding out effects may be a response to the public provision of services, or subsidies to NFPs. The management, employees and donors of NFPs may perceive that - as a result of this - the need of donated labour and private funding is less strong, thus rendering policies partly ineffective. In the US literature, there is strong evidence for crowding out, particularly regarding the relationship between government funding of public goods and private contributions to the provision of these goods (Glaeser and Schleifer (2001)).

\subsection{Conclusion}

When combining the insights from the theoretical and empirical literature, the picture that emerges is that there are no strong arguments here to favour organisations only because of their non-profit status, particularly in mixed markets. In particular, any form of government intervention that is specifically directed to NFP organisations may be hampered by various mechanisms, such as rents extraction and crowding out effects. Instead, in order to raise quality levels, government intervention will be more effective by regulatory measures that apply to all service providers, e.g. policies to increase market transparency or vouchers to increase accessibility. Or, to put this differently, the degree of market competition, as well as regulatory measures of the government are more important for market outcomes than any differences originating from the legal status of organisations.

16 Imposing price restrictions may be an alternative here, but this regulatory measure would be directed to all consumers, rather than being targeted at specific income groups.

17 Obviously, in case of high incontractability, the government may (also) opt for a more extreme policy intervention, namely by the public provision of services. 
From the analysis, we may conclude that the non-profit condition is not a sufficient condition for making a difference, in the sense that the quality or accessibility of services is better safeguarded than by FPs. This observation - or, stated differently, the absence of any proof that NFPs make a difference - in turn may discourage the provision of donated labour and private donations. It thus seems that public goals are best served by NFP organisations that clearly signal their missions and that - perhaps even more important - actively give account of their activities. This means that they inform customers about the quality of services that have been provided, as well as the specific markets and client groups they want to focus on. Otherwise, there is a large risk that - particularly for larger organisations - the distinction between FP and NFP status becomes largely anachronistic.

As a final remark, it should be stressed that our arguments against favouring NFPs by the government are certainly not an argument against NFPs. Instead, from our analysis we conclude that NFPs in fact can make a difference vis-à-vis FPs, particularly in markets where competition is low and/or when there are not many regulatory measures being taken by the government. In these markets, NFPs probably are capable of attracting intrinsically more motivated workers. But again, this is not an argument per se to stimulate NFPs, as one cannot (only) rely upon the legal status of these organisations.

\section{REFERENCES}

Blau, D. and J. Currie (2004), 'Preschool, day care, and afterschool care: Who's minding the kids', NBER Working Paper 10670.

Blau, D.M. and H.M. Mocan (2002), 'The supply of quality in child care centers', The Review of Economics and Statistics, 84 (3), pp. 483-496.

Cleveland, G. and M. Krashinsky (2004), 'The Quality Gap: A Study of Nonprofit and Commercial Child Care Centres in Canada', available from: http://childcarepolicy.net/pdf/NonprofitPaper.pdf

Cleveland, G. and M. Krashinsky (2005), 'The Nonprofit Advantage: Producing Quality in Thick and Thin Child Care Markets', available from: http://childcarepolicy.net/pdf/non-profitadvantage.pdf

Cutler, D. and J. Horwitz (2000), 'Converting Hospitals From Not-for-profit to For-profit Status: Why and What Effects?' in: D. Cutler, (eds.), The Changing Hospital Industry: Comparing Notfor-profit and For-profit Institutions, Chicago, University of Chicago Press, pp. 45-92.

CPB (2000), 'Arbeidsbemiddeling en -reïntegratie van werklozen; welke rol heeft de overheid te spelen?', CPB Werkdocument 118, Den Haag.

David, G. (2005), 'The Convergence Between For-profit and Nonprofit Hospitals in the United States', Working Paper, The Wharton School of Business University of Pennsylvania, Pennsylvania.

Devereaux, P.J., P.T.L. Choi, C. Lacchetti and B. Weaver (2002), 'A Systematic Review and Metaanalysis of Studies Comparing Mortality Rates of Private For-profit and Private Not-for-profit Hospitals', Canadian Medical Association Journal, 166 (11), pp. 1399-1406. 
Dranove, D. and R. Ludwick (1999), 'Competition and Pricing in Nonprofit Hospitals: A Reassessment of Lynk's Analysis', Journal of Health Economics, 18(1), pp.87-98.

Duggan, M.G. (2000), 'Hospital Ownership and Public Medical Spending', Quarterly Journal of Economics, 115 (4), pp. 1343-1373.

Eggleston, K., Y. Shen, J. Lau, C.H. Schmid and J. Chan (2006), 'Hospital Ownership and Quality of Care: What Explains the Different Results'? NBER Working Paper 12241.

Francois, P. (2001), 'What Should Government Contract Out?' The Role of the Public Sector Ethos, CMPO Bulletin, 2001/5, pp. 4-8.

Glaeser, E.L. and A. Schleifer (2001), 'Not-for-profit Entrepreneurs', Journal of Public Economics, 81, pp. 99-115.

Glaeser, E.L. (2002), 'The Governance of Not-for-profit Organizations', NBER Working Paper 8921.

Grabowski, D.C. and R.A. Hirth (2003), 'Competitive Spillovers Across Non-profit and Forprofit Nursing Homes', Journal of Health Economics, 22, pp. 1-22.

Gradus, R. and L. Bovenberg (2001), 'De economie van moeder Theresa', EconomischStatistische Berichten, 86 (4315), pp. 516-518.

Gray, B.H. and W.J. McNerney (1986), For-profit Enterprise in Health Care: The Institute of Medicine Study, New England Journal of Medicine, 81 (1), pp. 1523-1528.

Hansmann, H. (1980), 'The Role of Nonprofit Enterprise', Yale Law Journal, 89, pp. $835-901$.

Hansmann, H. (1996), 'The Changing Roles of Public, Private and Nonprofit Enterprise in Education, Health Care, and Other Human Services'. in: V.R. Fuchs (ed.), Individual and Social Responsibility: Child Care, Education, Medical Care and Long-term Care in America. Chicago, The University of Chicago Press.

Heckman, J., C.J. Heinrich and J. Smith (2002), 'The Performance of Performance Standards', Journal of Human Resources, 37, pp. 778-811.

Heinrich, C.J. (2000), 'Organizational Form and Performance: An Empirical Investigation of Nonprofit and For-Profit Job-Training Service Providers', Journal of Policy Analysis and Management, 19 (20), pp. 233-261.

Horwitz, J.R. (2005), 'Does Corporate Ownership Matter? Service Provision in the Hospital Industry' NBER Working Paper W11376.

Japel, C., R.E. Tremblay and S. Côté (2005), 'Quality Counts! Assessing the Quality of Daycare Services Based on the Quebec Longitudinal Study of Child Development', IRPP Choices, 11 (5), pp. 1-41.

Koning, P., J. Noailly and S. Visser (2007), 'Do not-for-profits make a difference? Evaluating the performance of non-profit vis-à-vis for-profit organisations in social services', CPB Document 142, The Hague.

Lakdawalla, D. and T. Philipson (2006), 'The Nonprofit Sector and Industry Performance', Journal of Public Economics, 90, pp. 1681-1698.

Lynk, W.J. (1995), 'Nonprofit Hospital Mergers and the Exercise of Market Power', Journal of Law and Economics, 38(2), pp. 437-461

Marmore, T.R., M. Schlesinger and R.W. Smithey (1986), 'A New Look at Nonprofits: Health Care Policy in a Competitive Age', Yale Journal of Regulation, 3 (2), pp. 313-349.

McClellan, M.B. and D. Staiger (2000), 'Comparing Hospital Quality at For-profit and Not-for profit Hospitals', NBER Working Paper 7324. 
Melnick, G., E. Keeler and J. Zwanziger (1999), 'Market Power and Hospital Pricing: Are Nonprofits Different?', Health Affairs, 18, (3), pp. 167-173.

Ministerie van Justitie (2006), 'Rapport van de projectgroep Rechtsvorm maatschappelijke onderneming', The Hague, Ministerie van Justitie.

Mocan, H.N. (1995), 'The Child Care Industry: Cost Functions, Efficiency, and Quality, NBER Working Paper 5293.

Mocan, H.N. and E. Terkin (2000), 'Nonprofit Sector and Part-time Work: An Analysis of employer - Employee Matched Data of Child Care Workers', NBER Working Paper 7977.

Morris, J.R. and S.W. Helburn (2000), 'Child Care Center Quality Differences: The Role of Profit Status, Client Preferences, and Trust', Nonprofit an Voluntary Sector Quarterly, 29 (3), pp. $377-$ 399.

Roomkin, M.J. and B.A. Weisbrod (1999), 'Managerial Compensation and Incentives in ForProfit and Nonprofit Hospitals', Journal of Law, Economics and Organization, 15, pp.750-781.

Ruhm, C. and C. Borkoski (2000), 'Compensation in the Nonprofit Sector', NBER Working Papers 7562, National Bureau of Economic Research,

Salamon, L.M., S.W. Sokolowski and R. List (2003), Global Civil Society - An Overview, Baltimore, The Johns Hopkins Institute for Policy Studies.

Shen, Y., K. Eggleston, J. Lau and C. Schmid (2005), 'Hospital Ownership and Financial Performance: A Quantitative Research Review', NBER Working Paper Series 11662.

Simpson, J. and R. Shin (1998), 'Do Nonprofit Hospitals Exercise Market Power?', International Journal of the Economics of Business, 5(2), pp.141-58.

Sloan, F.A. (2000), 'Non-for-profit Ownership and Hospital Behavior', in: A.J. Cutler and J.P. Newhouse, (eds.), Handbook of Health Economics, Elsevier, pp. 1141-1174.

Sloan, F.A., G.A. Picone, D.H. Taylor and S.Y. Chou (2001), 'Hospital Ownership and Cost and Quality of Care: Is there a Dime's Worth of Difference?', Journal of Health Economics, 20, pp.1-21

Spector, W.D., T.M. Selden and J.W. Cohen (1998), 'The Impact of Ownership Type on Nursing Home Outcomes', Health Economics, Vol. 7, pp. 639-653.

Stoll, M.A., E. Melendez and A. de Montrichard (2003), 'Will Community-Based Employment and Training Organizations be Disadvantages under WIA?' Recent Evidence on Participant Characteristics and Outcomes in Boston, Center for The Study of Urban Poverty Working Paper Series.

Sundell, K. (2000), 'Examining Swedish Profit and Nonprofit Child Care: The Relationships between Adult-to-Child Ratio, Age Composition in Child Care Classes, Teaching and Children's Social and Cognitive Achievements', Early Childhood Research Quarterly, 15, (1), pp. 91114.

Whitebook, M., C. Howes and D. Phillips (1990), 'Who Care? Child care teachers and the quality of care in America', Final Report of the National Child Care Staffing Study, Oakland, California, Child Care Employee Project. 